City University of New York (CUNY)

CUNY Academic Works

2016

\title{
Assessing Urban Greenhouse Gas Emissions in European Medium and Large Cities: Methodological Considerations
}

Peter Marcotullio

CUNY Hunter College

Andrea Sarzynski

University of Delaware

Jochen Albrecht

CUNY Hunter College

Niels Schulz

International Institute for Applied Systems Analysis, Austria

Jake Garcia

Guide Star

\section{How does access to this work benefit you? Let us know!}

More information about this work at: https://academicworks.cuny.edu/hc_pubs/643

Discover additional works at: https://academicworks.cuny.edu

This work is made publicly available by the City University of New York (CUNY).

Contact: AcademicWorks@cuny.edu 


\title{
Assessing Urban GHG Emissions in European Medium and Large Cities: Methodological Considerations
}

Peter J. Marcotullio, Andrea Sarzynski, Jochen Albrecht, Niels Schulz, and Jake Garcia

Total word count: 5,830

\begin{abstract}
Policymakers need clear, consistent, and reliable information about the location of greenhouse gases and drivers of emitting activity in order to design appropriate mitigating strategies. At the urban scale, there have been challenges in developing consistent and reliable emissions inventories. This chapter examines selected methods to determine greenhouse gas emissions at the urban scale. We describe the various criteria considered when constructing an urban greenhouse gas protocol including the definition of urban, the gasses that are measured, the source they come from, the scope of analysis and how the measurements are undertaken. We then present results for European medium and large sized cities derived from alternative methodologies to demonstrate the range of results. Finally, we briefly discuss the policy implications of the various approaches.
\end{abstract}

\section{Introduction}

Policymakers need clear, consistent, and reliable information about the location of greenhouse gases (GHG) and drivers of emitting activity in order to design appropriate mitigating strategies. Until recently, the most consistent and reliable information on GHG emissions has been for countries, following data collection protocols designed for the Intergovernmental Panel on Climate Change (IPCC). Focus has more recently shifted towards developing GHG emissions estimates at sub-national levels, especially for cities, where the majority of the global population and economic activity is now concentrated (UNFPA 2007). Existing research suggests that cities in aggregate are responsible for somewhere between 40 percent and 80 percent of global GHG emissions (Satterthwaite 2008). Considerable debate remains over appropriate methodologies for preparing city-level estimates of anthropogenic GHG emissions. Such debate has evolved because GHGs are typically not directly measured but estimated by extrapolating from activities that produce GHGs, such as fossil-fuel combustion.

The goal of this chapter is to overview some of the methods used to create urban GHG inventories and discuss the benefits and pitfalls of each using European medium and large sized cities. In the next section, we overview selected criteria for creating an inventory. This is followed by a presentation of urban GHG emissions results for European cities from different types of analyses. We conclude with a discussion of the implications for the use of different methods.

\section{Criteria to Consider}

As early as the 1980s, municipalities were preparing action plans for GHG emissions reductions based upon inventories (Harvey 1993). Over time the methods for estimating urban GHGs have increased in complexity and depth. As will be discussed below, the debate over 
appropriate methodologies for generating comparable urban emission inventories has yet to be resolved (for reviews see, Dhakal 2010; Kennedy et al. 2009). Generally concerns come under three categories: what geography should be included; what should be measured; and, how should it be measured (Bader and Bleischwitz 2009).

\subsection{What is urban?}

Defining the exact spatial and functional urban boundaries for measurement is of particular importance in generating accounts that represent conceptually comparable spheres of economic and social activity. Researchers use a number of different criteria to define urban areas and these differences have important implications (Marcotullio and Solecki 2010). GHG measurements sometimes are restricted to political borders of a municipality to reflect the legitimate scope of government and help in the development of climate change action plans, such as for Toronto, Vancouver, New York City, and Sydney (Tokyo Metropolitan Government 2007; City of Sydney 2008; Pander 2007; ICF International, Toronto Atmospheric Fund, and Office 2007; Dickinson and Desai 2010). Some researchers argue for even finer scale inventories. For example analysts have suggested that the county level in the USA is the best definition for urban, as it matches policy maker needs and is the smallest unit for which energy data are readily available (Parshall et al. 2010).

The urban sphere of influence extends well beyond the city's primary jurisdiction and immediate suburbs into outer suburbs and peri-urban lands. Upstream, urban residents depend on the production of emission intensive consumption items (i.e. agricultural goods, construction materials like steel and concrete). Downstream, they require the steady dissipation of waste products (e.g. in landfills and effluent from wastewater treatment plants). Urban areas are also hubs of regional and international transport, of which emissions are generated well beyond any urban related boundary. Some urban GHG studies therefore include local jurisdictions surrounding a central city, such as its immediate suburbs. For example, while the City of Chicago performed a municipal inventory of GHG emissions, they also estimated one for the metropolitan region (Chicago Climate Task Force 2008). While GHG emissions from larger urban agglomeration boundary are rare, some have been developing through spatial global and regional fossil fuel emissions estimates (Gurney et al. 2009; Raupach, Rayner, and Paget 2010). Other studies have estimated partial carbon footprints, including those of the 100 largest metropolitan areas in the USA in 2000 and 2005 (Brown, Southworth, and Sarzynski 2008). Finally, some researchers apply methods which systematically account for cross-boundary contributions of GHG emissions through consumption of key materials (Hillman and Ramaswami 2010). This issue of scope definition, to which we come back to below, further extends the boundaries of urban areas to those "distant elsewheres" mentioned by ecological footprint analysis (Rees and Wackernagel 1996) and the newer concept of urban land teleconnections (Seto et al. 2012).

Amongst cities that have been studied there is an emphasis on the large urban centers including New York City, Tokyo, London, Paris, Delhi, and Sao Paulo. This may be due to data availability, the political visibility of these larger cities and their importance in terms of share of urban GHG emissions (Dhakal 2009). Certainly, the field needs additional study of small- to mid- sized cities with a representative range of economic structure as most of the world's urban population lives in smaller urban centers (Satterthwaite 2007) and these centers might still be less constrained in expanding their existing infrastructure than very large settlements. 
Awareness about the implications of boundaries chosen for urban GHG emission inventories is critical for comparative studies and policy analysis. The sectoral and per capita GHG emissions of metropolitan regions arguably are different from those of core municipalities or even smaller units. Comparative studies would ideally encompass consistently-defined urban realms. For international studies, this is challenging, as countries define urban areas differently (see for example, United Nations 2010) and obtaining comparable data may be difficult.

\subsection{What is measured?}

Methodologies for urban GHG inventories need to be explicit about, at least, three interdependent questions: 1) Which GHGs are included? 2) What resolution of activities by sectors is considered? and, 3) What is the "scope” of the analysis? We examine each of these related issues separately.

First, researchers have a number of greenhouse gasses to include in analyses. The most important anthropogenic GHG emissions include carbon dioxide $\left(\mathrm{CO}_{2}\right)$, methane $\left(\mathrm{CH}_{4}\right)$, nitrous oxide $\left(\mathrm{N}_{2} \mathrm{O}\right.$ ), hydrofluorocarbons (HFCs), perfluorocarbons (PFCs) and sulfur hexafluoride $\left(\mathrm{SF}_{6}\right)$. For inventory development, however, most studies focus on $\mathrm{CO}_{2}$ and $\mathrm{CH}_{4}$ emissions. One reviewer suggests that GHGs other than $\mathrm{CO}_{2}$ are still unknown for urban areas (Dhakal 2010). There are two reasons for this outcome. First, $\mathrm{CO}_{2}$ accounts globally for approximately $77 \%$ of all anthropogenic GHG emissions and therefore is the most important GHG to consider (IPCC 2007). Second, non- $\mathrm{CO}_{2}$ GHGs research findings are typically extrapolated from activity data, such as consumption of GHG precursors (e.g. fertilizer use) or output from industrial processes or waste generated. Such data or specific conversion factors are often not available at the urban level. This focus on $\mathrm{CO}_{2}$ may be increasingly problematic as high impact GHGs could gain in their share of total GHGs in the coming years (CITATION xx) .

The second aspect of "what is measured" focuses on the detail of GHG emitting activity sectors or end-uses included in the study. Important end-use sectors include waste and wastewater, energy supply, transport, commercial and residential buildings, industry, agriculture and forestry (Dodman 2009; Weisz and Steinberger 2010). Kennedy et al. (2009), following the IPCC, suggest that methodologies for urban GHG emissions should include energy conversion and utilization (e.g. power production, vehicles, oil and gas production and fugitive emissions including emission leakage from natural gas and coal mining and gas flaring), waste, industrial processes and product use, and Agriculture, Forestry and other Land uses (AFOLU). Not all studies include these sources and GHG emission inventories vary greatly in this regard.

The third aspect of what to measure includes considerations for the allocation of emissions responsibility that exceed spatial system definitions, but occur at other locations. Local inventories often only include emissions from activities of businesses and residents located within the study area, known as “direct” emissions. Alternatively, measurements may also include emissions from activities located outside the local jurisdiction but induced through economic activities that are conducted within the jurisdiction, known as "indirect" or "deemed" emissions (Bader and Bleischwitz 2009; Lebel et al. 2007). For instance, power production and waste disposal may be conducted outside of cities but relate to the energy and waste disposal needs of urban residents and businesses. "Traditional” narrowly defined emissions inventories count only emissions that are produced within the study area, regardless of where the related good or service is ultimately consumed, thus placing the responsibility for emissions reduction with the production location (Dodman 2009). 
The World Resources Institute together with the World Business Council for Sustainable Development (WRI/WBCSD) prepared a reporting protocol for corporations (WBCSD and WRI 2004), which is increasingly used by researchers examining urban GHG emissions (Kennedy et al. 2009). The protocol addresses this issue by distinguishing among three "Scopes" of emissions. Scope 1 emissions are those from sources under the direct control of the organization, such as factories or vehicles. They are typically emissions produced in the geographical boundary of the city. Scope 2 emissions are from energy carriers (e.g. electricity, steam, heat, petroleum products) consumed by the organization, although emissions for their generation/energy conversion are produced elsewhere. If applied to urban areas, Scope 2 emissions include releases outside the geographical boundary of the city that enable energy carrier production for the city. Scope 3 emissions, also called embodied emissions (up- and downstream), are associated with extraction, production and transportation of products or services used by the residents of a city. These embodied emissions include those from food production, building material, waste treatment, and also from international aviation and marine transport, as far as it is necessary to sustain urban populations and economic activity. The concept of Scope 3 emission responsibility addresses the notion that all economic activity ultimately is driven by demand for products from consumers. Consequently some researchers argue that consumers should accept the responsibility for all emissions occurring along the entire value chain. In this case, inventories are called, consumption-based and allow for the generation of product and service prices to reflect emission related externalities. For equity reasons, it is important to allocate emissions where items are consumed and life-cycle, and consumption-based inventories, which consider cross scale interactions through trade are used to calculate these urban emissions “footprints” (Bader and Bleischwitz 2009; Dhakal 2010; Schulz 2010).

Advantages of consumption-based inventories at the national level include that they account for externalization of emissions through trade, cover emissions from international sea and air transport, increase mitigation options, and encourage cleaner production globally (Kondo, Moriguchi, and Shimizu 1998; Munksgaard and Pedersen 2001; Peters and Hertwich 2008). However, consumption-based inventories also suffer key disadvantages. First, they require more data, particularly about trade, complex calculations, and assumptions that increase data uncertainty. Second, consumption-based methods increase the risk of double-counting and incomparability of inventories across cities. Third, the methods shift the burden of mitigation from production to consumption, neither of which is optimal. For example, if the GHG emissions from a thermal power plant supplying energy to a city and located outside the city boundaries are allocated to the urban area, then the burden for reduction is placed upon the consumers. This approach alleviates responsibility for mitigation by the producer (Peters 2008). Given current practices and these weakness, scholars and practitioners are now calling for a shared responsibility between consumers and producers (Lenzen et al. 2007; Peters 2010).

\subsection{How is it measured?}

There are a variety of ways in which GHG emissions inventories can be compiled and these also vary by gas (WRI 2002). The most accurate measurements are sensed or measured directly, but the most common are estimates based upon activity based extrapolations using emission factors. Two general approaches have been developed to estimate urban GHG emissions. The bottom-up approach begins with defining the study area boundary and relevant activities. Often, bottom-up studies are conducted by local governments or in conjunction with 
local officials and authorities. A primary benefit of bottom-up measurement is its attention to local context, specific activity levels, and data availability. The bottom-up approach is often relatively comprehensive in scope and accurate in measurement. Various tools have been developed to assist cities in conducting bottom-up emissions measurements (Box 1), but the use of measurement tools allows considerable discretion regarding geographic boundaries, scope of included activities, and data sources (Bader and Bleischwitz 2009).

\section{Box 1: Tools for Preparing Local GHG Emissions Inventories}

Over the last few years a number of different protocols for estimating local GHG emissions have been developed for use by municipalities, researchers and individuals. Nikolas Bader and Raimund Bleischwitz (2009) reviewed six tools that have been used in Europe including: Project 2 Degrees (developed by ICLEI, Microsoft, and the Clinton Climate Foundation; in English; used by some C40 cities); GRIP (developed by University of Manchester, UK; in English; used by several European regions); $\mathrm{CO}_{2}$ Grobbilanz (developed by Austria's energy agency; in German only); Eco2Regio (developed by Ecospeed; in German,

French, and Italian; used by several Climate Alliance cities); Bilan Carbone (developed by French energy agency; in French); and the $\mathrm{CO}_{2}$ Calculator (developed by Danish National Environmental Research Institute; in Dutch). One of the major findings of this study was that the six tools vary substantially according to the GHGs included ( $\mathrm{CO}_{2}$ vs. other GHGs), the global warming potential (GWP) values used to calculate $\mathrm{CO}_{2}$-equivalents of other GHGs, the scope of measurement (direct vs. indirect), the definitions of sectors, how emissions were quantified (top-down vs. bottom-up), how closely the tool follows the IPCC

guidelines, and usability of the tool (e.g., simplicity of use, available languages). Given these differences, Bader and Bleischwitz conclude that the tools, developed in isolation from each other, making their resulting measurements "hardly comparable" across cities or regions. The authors recommend the development of a common tool for conducting local inventories that include all six of the major GHGs covered by the IPCC guidelines, use the most recent GWP values, a complete or at least consistent set of emissions sources, consistent sectoral definitions, and both direct and indirect emissions following a consistent protocol (reporting embedded or life-cycle emissions separately). The authors of this chapter add that the common tool also needs to include a conceptually-consistent definition of the "urban" or "region” geography for measurement, as described below.

Source: Bader and Bleischwitz. 2009

An alternative measurement approach is to construct local emissions profiles from national-, regional- or global-level emissions measurements, using a consistent methodology for downscaling. This top-down approach can range from simple to more complex, "hybrid" methodologies. For instance, a simple top-down analysis could estimate local emissions using only the number of people living or working in the local area and the average annual GHG emissions per person across all source categories, according to national statistics. While easy to calculate, these simple estimations, they can be misleading, particularly since they do not reflect urban scale variation in economic structure and activity patterns. In addition, simple approaches do not provide much insight when comparing across cities, as any apparent variation reflects only the population size of the cities rather than any meaningful differences in the actual location or source activities of emissions.

Other top-down approaches tailor their inventories somewhat to local circumstances and data availability, even if relying heavily on national, regional or global statistics. For instance, local emissions from electricity production could be estimated by multiplying the amount of electricity produced locally in megawatt-hours (using production data from the power plant) by the regional or national average GHG emissions released per unit of electricity. Similar estimates could be made for other activities, where outcome estimates and relevant "multipliers" are available.

A more complex top-down method has been developed by Marcotullio et al. (2010). For GHG emissions, they used the Emissions Database for Global Atmospheric Research (EDGAR), version 4. ${ }^{1}$ EDGAR includes GHG emissions from fourteen source categories in global grids at

\footnotetext{
${ }^{1}$ (European Commission Joint Research Centre (JRC)/Netherlands Environmental Assessment Agency (PBL) 2009)
} 
$0.1^{\circ}$ spatial resolution. For identifying urban geographies and their populations, they used the Global Rural Urban Mapping Project (GRUMP) data. ${ }^{2}$ Emissions estimates for European cities are presented in the next section, using this approach.

Top-down approaches have several advantages over bottom-up approaches, including universally comparable definitions of urban areas, the potential to include all major GHG compounds in the analysis for urban centers (including some aviation and navigation emissions), avoidance of double-counting issues, a large number of standardized sources to examine the influences of emissions, and a uniform and replicable methodology to map and analyze emissions. Indeed, top-down methods may be applied at various temporal and spatial scales depending on the location and frequency of measurements, providing useful information about processes and patterns of emissions (Pataki et al. 2006).

\subsection{Summary}

Urban emissions measurements vary considerably in their operational details. Several issues can be conceptualized as a set of continuums within which researchers choose to build their inventories (Table 1). While complex, these topics are a sub-set of a comprehensive range of source activities and estimating techniques. As Kates et al. (1998, pp. 22) suggest, "there is no end to the minutiae of detailed information that is necessary to fully characterize greenhouse gas emissions and emission reduction opportunities.” In principle, comprehensive measurements would include all major GHGs (including carbon dioxide, methane, nitrous oxide, chlorofluorocarbons, and other hydrocarbons) and at least all of the major source activities required to be included in national-level emissions inventories according to the IPCC's protocol. Obtaining such comprehensive emissions data for cities is difficult under the best of circumstances. Most often, urban inventories are limited by available data at the appropriate scale, requiring either a limitation in scope or sector that excludes some relevant activities, or top-down methods to estimate local emissions.

Table 1: Summary of issues to cover in urban GHG inventories

\begin{tabular}{|c|c|}
\hline Variable & Continuum \\
\hline \multicolumn{2}{|l|}{ What is urban? } \\
\hline Urban Boundary & $\rightarrow$ All urban GHG emitting activities \\
\hline \multicolumn{2}{|c|}{ What is measured? } \\
\hline GHG measured & $\rightarrow$ All 6 GHGs in Kyoto Protocol \\
\hline GWP values & Values from $2^{\text {nd }}$ IPCC report \\
\hline Scope & Only direct emissions $\longrightarrow$ Direct, indirect and life-cycle emissions \\
\hline Sectors & Limited sectors, different definitions $\longleftrightarrow$ All sectors with IPCC definitions \\
\hline \multicolumn{2}{|l|}{$\begin{array}{l}\text { How is it } \\
\text { measured? }\end{array}$} \\
\hline Method & $\begin{array}{l}\text { Top down (default emission factors) } \longleftrightarrow \text { Bottom up (regional/local emission } \\
\text { factors) }\end{array}$ \\
\hline
\end{tabular}

\footnotetext{
${ }^{2}$ See http://www.earth.columbia.edu/news/2005/story03-07-05.html
} 


\subsection{Assessment of GHG Emissions from European Cities}

Estimates of GHG emissions for individual cities vary considerably within the literature. For example, estimates of annual GHG emissions per person in London range from 1.2 metric tons (Sovocool \& Brown, 2010) to 6.2 tons (Greater London Authority 2010) to 9.6 tons (Kennedy et al. 2009).

Given the variety of techniques used in urban GHG inventories, we compare results from three estimation efforts that aimed to produce comparable figures across cities. The first two efforts follow a "bottom-up" approach. The first effort examined GHG emissions in 44 cities around the world, including 20 cities from across Europe, using data from around 2005. The estimation methodology was standardized across each of these cities and reflects a consumptionbased approach (Kennedy et al. 2009). ${ }^{3}$ The second effort, conducted for the European Commission, examined a large number of cities in Eastern, Northern, and Southern Europe with data mostly from 1998-2001. The protocol was not as rigorously standardized as the first effort, but it has been used as the basis for climate change mitigation and adaptation strategy development in Europe (European Commission 2003). The third effort reflects our own "topdown" research, described briefly above. We used spatially disaggregated global datasets to estimate GHG emissions from urban centers worldwide, using data for 2000. This approach contains Scope 1 and 2 GHG related activities, as well as some airline and navigation emissions associated with urban activities. More details of the methods are presented in other publications (Marcotullio, Sarzynski, Albrecht, Schulz, et al. 2013).

Bottom up GHG emissions estimates vary widely across the sample of 42 European cities covered by at least two of the reports (Table 2). Estimates in the European Commission (2003) study ranged from 2.5 metric tons per person in Oslo to 11.9 metric tons per person in Pori (Finland), for an average of 6.9 metric tons per person across 25 cities. Kennedy et al. (2009) found slightly higher estimates, ranging from a low of 3.5 metric tons per person in Oslo to 16.0 tons per person in Stuttgart (Germany), for an average of 8.25 metric tons per person across 20 cities. Our estimates ranged from a low of 0.7 metric tons in Blagoevgrad (Bulgaria) to 16.8 metric tons per person in Pori (Finland), for an average of 6.4 metric tons per person across 42 cities (Marcotullio, Sarzynski, Albrecht, and Schulz 2013). The higher average values from Kennedy et al. (2009) likely result from their consumption-based approach, which includes some indirect emission sources such as waste treatment not included in the other two studies. On the other hand, the differences between the top down and bottom up approaches may largely be due to the differences in data resolution, definition of urban, gases and sources included and the year of study. It is important to point out that we do not expect that the top-down approach be useful at the urban scale, as differences in the quality of infrastructure and intra-urban ranges cannot be captured. On the other hand, the top-down approach is helpful in generating data for a larger number of urban areas and at the regional and global scales the differences between the bottom up and top-down estimates largely disappear (Marcotullio, Sarzynski, Albrecht, and Schulz 2013; Marcotullio, Sarzynski, Albrecht, Schulz, et al. 2013). Hence, while the top-down approach might be useful for policy at the regional scale, it is not a substitute for intensive bottom-up studies upon which to base specific urban policy.

\footnotetext{
${ }^{3}$ This study, however, includes various definitions of urban including “city,” "metropolitan region,” “province” and "region.” Those from the Greenhouse Gas Regional Inventory Protocol (GRIP) project included in this study typically use larger urban area definitions (see http://www.grip.org.uk/Home.html).
} 
When compared to selected cities elsewhere (Kennedy et al. 2009), the GHG emissions from urban areas in Europe demonstrate general patterns. Urban GHG emissions estimates for cities in North America are typically higher than those of Europe, with a regional average approximately double that found in Europe (Table 3). Indeed, only a few cities in Germany have estimated emissions levels falling within the range seen in the selected North American cities. Moreover, the GHG emissions estimates for European cities are considerably higher than for South American cities. Of the selected Asian urban areas, GHG emissions are typically higher than those in European urban centers with the exception of Tokyo, which falls within the range of estimates for European cities.

Comparison of our results with the other two efforts illustrates the difficulty of comparing individual city estimates calculated with different methodologies. For instance, only five of our city estimates fell within 10\% of published values from the other two reports: Catania (Italy), Milano (Italy), Prague (Czech Republic), Turku (Finland), and Veneto (Italy). The majority of city estimates in our sample fell within $50 \%$ of the values published by the other reports, with a slight tendency to fall below the estimates published elsewhere. Yet three of our city estimates are more than double those found in the literature, for Brussels (Belgium), Oslo (Norway), and Stockholm (Sweden).

A significant amount of discrepancy among the studies cited can be traced back to variations in study design (Kennedy et al. 2009, for example, is in itself a compilation of studies) and inconsistencies with respect to the geographic boundaries studied and sources/gases included. The authors of this chapter examined the effect of different spatial definitions of "urban" from high-density areas within the confines of legal boundaries and urbanized areas based on GRUMP boundaries (Balk et al. 2006) to extensive periurban inclusion areas with high intensity agriculture (especially Germany and Greece) and the majority of energy production (see Figure 1). Table 4 indicates the Europe-wide variation of the contribution of different emissions sources in three different definitions of the term 'urban." Some emission sources, such as industrial production and transportation, are distributed in an intuitively understandable manner. Others, such as land use change, or agriculture and waste, have a surprisingly large impact in both the traditional metropolitan area and periurban context. These summary figures oscillate again widely when broken down into different countries/regions. Periurban land use change is the source of between $40 \%$ and $78 \%$ of all GHGs in that zone. In Slovenia, over $90 \%$ of its industrial emissions originate outside metropolitan areas. Slovakia's urbanized areas contribute to only $16 \%$ of total GHG emissions in that country. It is therefore not surprising that the literature cited in this section seems so contradictory; the choices made with respect to geographic boundaries and included sources can have dramatic effects on final GHG estimates for urban areas (Albrecht et al., 2013).

\section{Discussion}

Urban researchers have striven to develop rigorous protocols for standardizing GHG emission estimates for policy and theoretical work. While there has been much progress, several drawbacks continue to plague this work and result in a general lack of comparability of findings across studies (Bader and Bleischwitz 2009; Ramaswami et al. 2008). It is therefore not surprising that different inventory schemes produce disparate results.

More importantly, the differences in results reflect differences in the purposes for which the studies are produced. As noted by others, there are two types of studies on $\mathrm{CO}_{2}$ emissions. 
One type of study inventories local emissions in single areas to directly support local policy objectives. They define detailed baselines that municipalities can use to judge performance. They are also awareness raising, educational, and participatory tools to facilitate increased understanding of and participation in lowering GHG emissions. The results from individual case studies reflect such detailed local context and knowledge, and are difficult to generalize to other urban areas. At the same time, the top-down approach is limited in that the resolution of the data is not fine enough to be of use at the urban scale. .

Another type of study analyzes a cross-section of localities to derive general relationships between energy use and patterns of urban development (Parshall et al. 2010). As such, these types of studies are useful for generating policy priorities at higher levels of governance (nations, regional international agreements). It is at this level that top-down analyses might be most useful. Regionally comparable studies of urban GHG emissions can identify outliers for further examination with respect to policy decisions. They could point to those urban areas that may have policy or other actions that are lowering or increasing emissions. They also could be used to identify other influences on GHG emissions, including urban form, socio-economic characteristics, and biophysical context.

Given the different purposes for development of bottom-up individual case studies and top-down regional studies, we suggest that the findings from both types of analyses must be used together to support local and regional actions (Stohl et al. 2010). We also advise the continued development of rigorous protocols for estimating comparable GHG emissions from urban areas worldwide, which would both advance our scientific knowledge as well as aid in identification of mitigation potentials and priorities. 


\section{References}

Albrecht J, Marcotullio P, Sarzynski A and N Schulz, 2013. The role of suburbia in the distribution of greenhouse gas emissions. Proceedings of the Joint AESOP/ACSP Congress in Dublin, Ireland, 15-19 July 2013.

Bader, N., and R. Bleischwitz. 2009. Measuring urban greenhouse gas emissions: The challenge of comparability. Survey and Perspectives Integrating Environment \& Society 2 (3):7-21.

Brown, M. A., F. Southworth, and A. Sarzynski. 2008. Shrinking the carbon footprint of metropolitan America. Washington DC: Brookings Institute Metropolitan Policy Program.

Chicago Climate Task Force. 2008. Climate Change and Chicago. Chicago: Chicago Climate Task Force.

City of Sydney. 2008. Local government area greenhouse gas emissions. Sydney: http://www.cityofsydney.nsw.gov.au/environment/GreenhouseAndAirQuality/CurrentSta tus/GreenhouseGasEmissions.asp (accessed on 20/09/11).

Dhakal, S. 2009. Urban energy use and carbon emissions from cities in China and policy implications. Energy Policy 37 (11):4208-4219. 2010. GHG emission from urbanization and opportunities for urban carbon mitigation. Current Opinion in Environmental Sustainability 2 (4):277-283.

Dickinson, J., and R. Desai. 2010. Inventory of New York City Greenhouse Gas Emissions. New York: Mayor's Office of Long-Term Planning and Sustainability.

Dodman, D. 2009. Blaming cities for climate change? An analysis of urban greenhouse gas emissions inventories. Environment and Urbanization 21 (1):185-201.

European Commission. 2003. European Common Indicators, Towards a Local Sustainability Profile. Milano, Italy: Ambiente Italia Research Institute.

European Commission Joint Research Centre (JRC)/Netherlands Environmental Assessment Agency (PBL). 2009. Emission Database for Global Atmospheric Research (EDGAR), release version 4.0, ed. http://edgar.jrc.ec.europa.eu/.

Greater London Authority. 2010. Delivering London’s energy future. London: Greater London Authority.

Gurney, K. R., D. L. Mendoza, Y. Zhou, M. L. Fischer, C. C. Miller, S. Geethakumar, and S. De La Rue Du Can. 2009. High resolution fossil fuel combustion CO2 emission fluxes for the United States. Environmental Science \& Technology 43 (14):5535-5541.

Harvey, L. D. D. 1993. Tackling urban CO2 emissions in Toronto. Environment 37 (7):16-20 and 33-44.

Hillman, T., and A. Ramaswami. 2010. Greenhouse gas emission footprints and energy use benchmarks for eight U.S. cities. Environmental Science and Technology 44 (6):19021910.

ICF International, Toronto Atmospheric Fund, and T. E. Office. 2007. Greenhouse Gases and Air Pollutantsin the City of Toronto, Toward a Harmonized Strategy for Reducing Emissions. Toronto: Toronto Atmospheric Fund and Toronto Environment Office.

IPCC. 2007. Climate Change 2007: Synthesis Report. Geneva, Switzerland: IPCC.

Kates, R. W., M. W. Mayfield, R. D. Torrie, and B. Witcher. 1998. Methods for estimating greenhouse gases from local places. Local Environment 3 (2):279-297.

Kennedy, C. A., A. Ramaswami, S. Carney, and S. Dhakal. 2009. Greenhouse gas emission baselines for global cities and metropolitan regions. In Proceeding from Cities and 
Climate Change: Responding to an Urgent Agenda, 28-30 June. Marseille, France: World Bank, Government of France.

Kondo, Y., Y. Moriguchi, and H. Shimizu. 1998. CO2 emissions in Japan: Influences of imports and exports. Applied Energy 59 (2-3):163-174.

Lebel, L., P. Garden, M. R. N. Banaticla, R. D. Lasco, A. Contreras, A. P. Mitra, C. Sharma, H. T. Nguyen, G. L. Ooi, and A. Sari. 2007. Integrating Carbon Management into the Development Strategies of Urbanizing Regions in Asia: Implications of Urban Function, Form, and Role. Journal of Industrial Ecology 11 (2):61-81.

Lenzen, M., J. Murray, F. Sack, and T. Wiedmann. 2007. Shared producer and consumer responsibility - Theory and practice. Ecological Economics 61 (1):27-42.

Marcotullio, P. J., A. Sarzynski, J. Albrecht, and N. Schulz. 2013. A top-down regional assessment of urban greenhouse gas emissions in Europe. Ambio: A Journal of the Human Environment doi:10.1007/s13280-013-0467-6.

Marcotullio, P. J., A. Sarzynski, J. Albrecht, N. Schulz, and J. Garcia. 2013. The geography of global urban greenhouse gas emissions: An exploratory analysis. Climatic Change 121 (4):621-634.

Marcotullio, P. J., and W. Solecki. 2010. What is a city? Old debate, new implications. Urbanization and Global Environmental Change Newsletter, 7-11.

Munksgaard, J., and K. A. Pedersen. 2001. CO2 accounts for open economies: producer or consumer responsibility? . Energy Policy 29 (4):327-334.

Pander, S. 2007. Climate Protection Progress Report - 2007, ed. Standing Committee on Planning and the Environment, 31: City of Vancouver.

Parshall, L., K. Gurney, S. A. Hammer, D. Mendoza, Y. Zhou, and S. Geethakumar. 2010. Modeling energy consumption and CO2 emissions at the urban scale: Methodological challenges and insights from the United States. Energy Policy 38 (9):4765-4782.

Pataki, D. E., R. J. Alig, A. S. Fung, N. E. Golubiewski, C. A. Kennedy, E. G. McPherson, D. J. Nowak, R. V. Pouyat, and P. Romero-Lankao. 2006. Urban ecosystems and the North American carbon cycle. Global Change Biology 12 (11):2092-2102.

Peters, G. P. 2008. From production-based to consumption-based national emission inventories. Ecological Economics 65 (1):13-23.

. 2010. Carbon footprints and embodied carbon at multiple scales. Current Opinion in Environmental Sustainability 2 (4):245-250.

Peters, G. P., and E. G. Hertwich. 2008. CO2 embodied in international trade with implications for global climate policy. Environmental Science \& Technology 42 (5):1401-1407.

Ramaswami, A., T. Hillman, B. Janson, M. Reiner, and G. Thomas. 2008. A demand-centered methodology for city-scale greenhouse gas inventories. Environmental Science \& Technology 42 (17):6455-6461.

Raupach, M. R., P. J. Rayner, and M. Paget. 2010. Regional variations in spatial structure of nightlights, population density and fossil-fuel CO2 emissions. Energy Policy 38 (9):4756-4764.

Rees, W., and M. Wackernagel. 1996. Urban ecology footprints: why cities cannot be sustainable - and why they a key to sustainablility. Environmental Impact Assessment Review (16):223-248.

Satterthwaite, D. 2007. The transition to a predominantly urban world and its underpinnings. In IIED Human Settlements Discussion Paper Series, 91. London. 
2008. Cities' contribution to global warming: notes on the allocation of greenhouse gas emissions. Environment and Urbanization 20 (2):539-549.

Schulz, N. 2010. Delving into the carbon footprint of Singapore - comparing direct and indirect greenhouse gas emissions of a small and open economic system. Energy Policy 38 (9):4848-4855.

Seto, K. C., A. Reenberg, C. G. Boone, M. Fragkias, D. Haase, T. Langanke, P. Marcotullio, Darla K. Munroe, B. Olah, and D. Simon. 2012. Urban Land Teleconnections and Sustainability. Proceedings of the National Academy of Science 109 (18):doi: 10.1073/pnas.1117622109.

Stohl, A., J. Kim, S. O'Doherty, J. Muhle, P. K. Salameh, T. Saito, M. K. Vollmer, D. Wan, R. F. Weiss, B. Yao, Y. Yokouchi, and L. X. Zhou. 2010. Hydrocholorofluorocarbon and hydrofluorocarbon emission in East Asia determined by inverse modeling. Atmospheric Chemistry and Physics 10 (8):3545-3560.

Tokyo Metropolitan Government. 2007. Tokyo Climate Change Strategy, A Basic Policy for the 10-year Project for a Carbon-Minus Tokyo. Tokyo: TMG.

UNFPA. 2007. State of the World Population: Unleashing the Potential of Urban Growth. New York: United Nations Population Fund.

United Nations. 2010. World Urbanization Prospects: 2009 Revisions. New York: DESA, UN.

WBCSD and WRI. 2004. A Corporate Accounting and Reporting Standard. Conches-Geneva and Washington, DC: World Business Council for Sustainable Development and World Resources Institute.

Weisz, H., and J. K. Steinberger. 2010. Reducing energy and material flows in cities. Current Opinion in Environmental Sustainability 2 (3):185-192.

WRI. 2002. Designing a Customized Greenhouse Gas Calculation Tool. Washington DC: World Resources Institute. 
Table 2

\begin{tabular}{|c|c|c|c|c|c|}
\hline \multicolumn{5}{|c|}{$\begin{array}{l}\text { Comparison of selected previous } \mathrm{GHG} \text { results to our approach results for European urban areas } \\
\text { (tons } \mathrm{CO}_{2} \text { equivalents) }\end{array}$} & \multirow{2}{*}{$\begin{array}{r}\text { This study } \\
\text { EDGAR- Total } \\
\text { GHG emissions } \\
\text { per capita }\end{array}$} \\
\hline Region / urban area & Country & Study date & Source & $\begin{array}{r}\text { Total } \\
\text { GHG emissions } \\
\text { per capita }\end{array}$ & \\
\hline \multicolumn{6}{|l|}{ Southern Europe } \\
\hline Athens & Greece & 2005 & Kennedy et al 2009 & 10.4 & 3.9 \\
\hline Ancona & Italy & $1998-2001$ & European Common Indicators, 2003. & 7.0 & 5.1 \\
\hline Bologna & Italy & 2005 & Kennedy et al 2009 & 11.1 & 4.3 \\
\hline Catania & Italy & 1995 & European Common Indicators, 2003. & 5.0 & 5.4 \\
\hline Ferrara & Italy & 1997 & European Common Indicators, 2003. & 9.2 & 1.6 \\
\hline Naples & Italy & 2005 & Kennedy et al 2009 & 4.0 & 5.5 \\
\hline Nord Milano & Italy & $1998-2001$ & European Common Indicators, 2003. & 8.8 & 8.1 \\
\hline Parma & Italy & 1998-2001 & European Common Indicators, 2003. & 8.4 & 4.4 \\
\hline Pavia & Italy & $1998-2001$ & European Common Indicators, 2003. & 6.0 & 2.9 \\
\hline Provincia Torino & Italy & $1998-2001$ & European Common Indicators, 2003. & 7.6 & 8.4 \\
\hline Veneto & Italy & 2005 & Kennedy et al 2009 & 10.0 & 10.2 \\
\hline Verbania & Italy & 1998-2001 & European Common Indicators, 2003. & 8.6 & 2.2 \\
\hline Porto & Portugal & 2005 & Kennedy et al 2009 & 7.3 & 4.3 \\
\hline Ljubljana & Slovenia & 2005 & Kennedy et al 2009 & 9.5 & 6.1 \\
\hline Maribor & Slovenia & $1998-2001$ & European Common Indicators, 2003. & 8.7 & 4.7 \\
\hline A Coruna & Spain & 1998-2001 & European Common Indicators, 2003. & 7.1 & 5.9 \\
\hline Barcelona & Spain & $1998-2001$ & European Common Indicators, 2003. & 3.6 & 4.9 \\
\hline Barcelona & Spain & 2006 & Kennedy et al 2009 & 4.2 & 4.9 \\
\hline Burgos & Spain & $1998-2001$ & European Common Indicators, 2003. & 8.0 & 5.3 \\
\hline Madrid & Spain & 2005 & Kennedy et al 2009 & 6.9 & 5.8 \\
\hline Pamplona & Spain & $1998-2001$ & European Common Indicators, 2003. & 3.5 & 5.4 \\
\hline Victoria-Gasteiz & Spain & 1998-2001 & European Common Indicators, 2003. & 7.2 & 4.0 \\
\hline \multicolumn{6}{|l|}{ Eastern Europe } \\
\hline Blagoevgrad & Bulgaria & 1998-2001 & European Common Indicators, 2003. & 3.6 & 0.7 \\
\hline Prague & Czech Republic & 2005 & Kennedy et al 2009 & 9.3 & 9.0 \\
\hline Gdansk & Poland & NA & European Common Indicators, 2003. & 6.9 & 6.1 \\
\hline \multicolumn{6}{|l|}{ Northern Europe } \\
\hline Aarhus & Denmark & 1998-2001 & European Common Indicators, 2003. & 7.7 & 6.8 \\
\hline Helsinki & Finland & 2005 & Kennedy et al 2009 & 7.0 & 9.8 \\
\hline Pori & Finland & 1998-2001 & European Common Indicators, 2003. & 11.9 & 16.8 \\
\hline Tampere & Finland & 1998-2001 & European Common Indicators, 2003. & 8.6 & 7.0 \\
\hline Turku & Finland & $1998-2001$ & European Common Indicators, 2003. & 10.7 & 10.4 \\
\hline Oslo & Norway & 1998-2001 & European Common Indicators, 2003. & 2.5 & 7.6 \\
\hline Oslo & Norway & 2005 & Kennedy et al 2009 & 3.5 & 7.6 \\
\hline Malmoe & Sweden & $1998-2001$ & European Common Indicators, 2003. & 4.8 & 7.9 \\
\hline Stockholm & Sweden & 2005 & Kennedy et al 2009 & 3.6 & 7.7 \\
\hline Stockholm & Sweden & 1998-2001 & European Common Indicators, 2003. & 3.9 & 7.7 \\
\hline Vaxjoe & Sweden & $1998-2001$ & European Common Indicators, 2003. & 3.8 & 1.9 \\
\hline Bristol & United Kingdom & 1998-2001 & European Common Indicators, 2003. & 9.4 & 6.6 \\
\hline London & United Kingdom & 2003 & Kennedy et al 2009 & 9.6 & 7.1 \\
\hline Glasgow & United Kingdom & 2004 & Kennedy et al 2009 & 8.8 & 11.6 \\
\hline \multicolumn{6}{|l|}{ Western Europe } \\
\hline Brussels & Belgium & 2005 & Kennedy et al 2009 & 7.5 & 15.2 \\
\hline Paris & France & 2005 & Kennedy et al 2009 & 5.2 & 7.6 \\
\hline Frankfurt & Germany & 2005 & Kennedy et al 2009 & 13.7 & 2.5 \\
\hline Hamburg & Germany & 2005 & Kennedy et al 2009 & 9.7 & 6.7 \\
\hline Stuttgart & Germany & 2005 & Kennedy et al 2009 & 16.0 & 8.0 \\
\hline Geneva & Switzerland & 2005 & Kennedy et al 2009 & 7.8 & 3.1 \\
\hline Average & & & & 10.0 & 7.2 \\
\hline
\end{tabular}

Source: Kennedy et al 2009, European Common Indicators 2003, this study 
Table 4. Percentage of European GHG emissions by source in different definitions of urban areas.

\begin{tabular}{|l|r|r|r|r|}
\hline \multicolumn{1}{|c|}{ Source } & City Core & Urbanized & Periurban & Rural \\
\hline \hline Energy use in manufacturing and construction & 14.6 & 49.9 & 31.6 & 3.9 \\
\hline Energy use in transportation & 16.0 & 42.2 & 34.5 & 7.4 \\
\hline Energy use from other sources and fugitive emissions & 12.9 & 31.2 & 44.0 & 11.9 \\
\hline Industrial processes & 9.8 & 47.8 & 38.1 & 4.0 \\
\hline Agriculture & 1.0 & 12.1 & 63.2 & 23.7 \\
\hline Land use change & 1.6 & 10.2 & 69.1 & 19.2 \\
\hline Waste & 11.4 & 37.6 & 40.8 & 10.1 \\
\hline Other anthropogenic sources & 1.3 & 12.0 & 58.1 & 28.6 \\
\hline Total, Europe-wide & 7.9 & 27.7 & 49.5 & 14.8 \\
\hline
\end{tabular}


Table 3

\begin{tabular}{llrr}
\hline $\begin{array}{l}\text { GHG emissions per capita from non-European Cities } \\
\text { (tons } \mathrm{CO}_{2} \text { equivalents) }\end{array}$ & Study date & $\begin{array}{r}\text { GHG emissions } \\
\text { per capita }\end{array}$ \\
Urban area & Country & 2005 & 19.4 \\
\hline \hline Denver & United States of America & 13.0 \\
Los Angeles & United States of America & 2000 & 10.5 \\
New York City & United States of America & 2005 & 11.6 \\
Toronto & Canada & 2005 & 13.6 \\
Average & & & \\
& & & 2.1 \\
Rio de Janeiro & Brazil & 1998 & 1.4 \\
Sao Paulo & Brazil & 2000 & 1.8 \\
Average & & & \\
& & & 10.7 \\
Bangkok & Thailand & 2005 & 10.1 \\
Beijing & China & 2006 & 11.7 \\
Shanghai & China & 2006 & 11.1 \\
Tianjin & China & 1998 & 4.9 \\
Tokyo & Japan & 2006 & 9.7 \\
Average & & & \\
Cape Town & & 2006 & 7.6 \\
& & & \\
\hline
\end{tabular}

Source: Kennedy, et al, 2009 
Figure 1. Extent of urban versus non-urban areas in Europe.

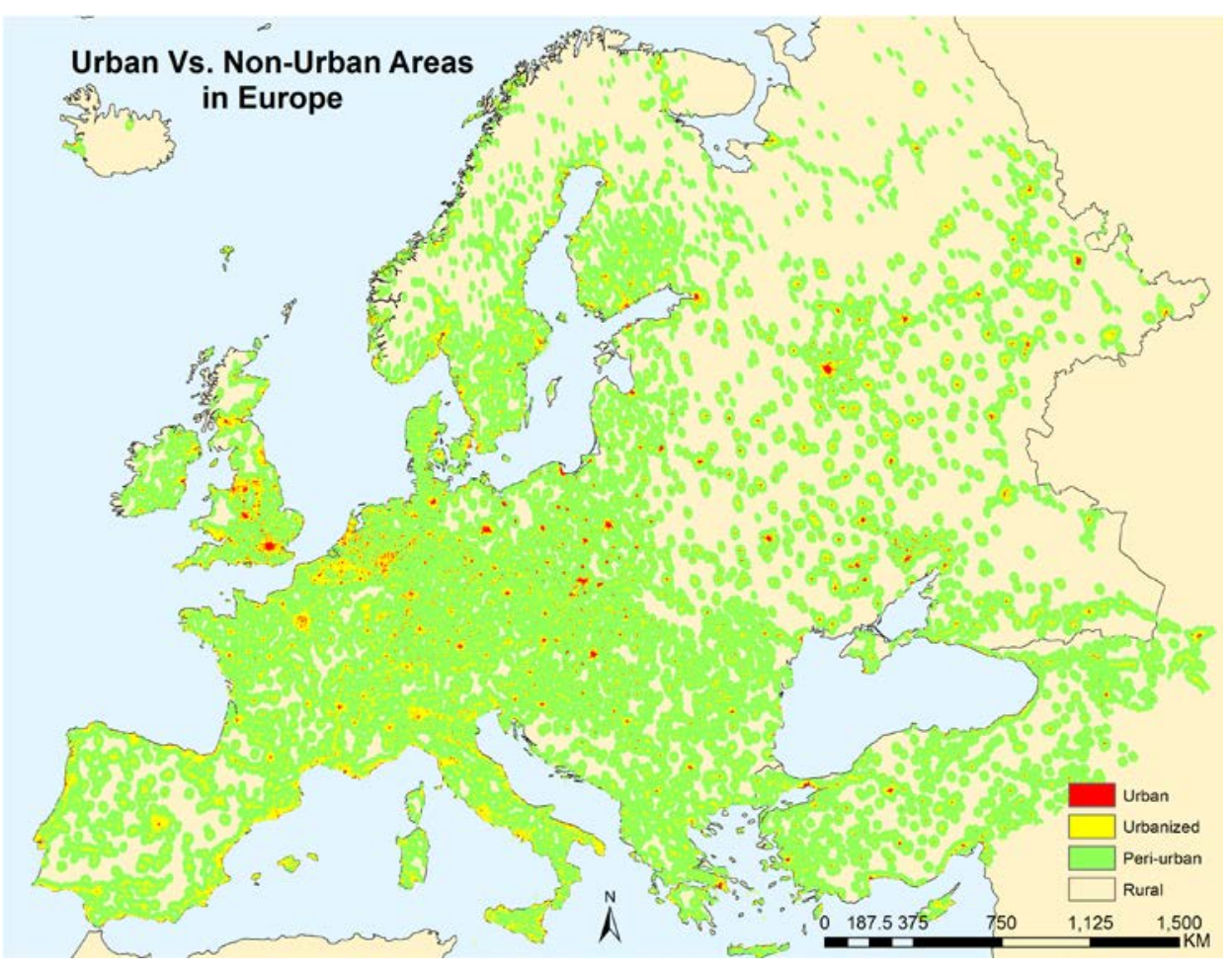

